\title{
Erratum
}

\section{The FinTech Revolution and Financial Regulation: The Case of Online Supply-Chain Financing - ERRATUM}

\author{
Chang-hsien TSAI* and Kuan-Jung PENG**
}

doi: https://doi.org/10.1017/als.2016.65, Published by Cambridge University Press, 15 March 2017.

The above paper contained the following error: The full contact details of the authors, a bibliographical note of the authors containing affiliation details and acknowledgements were omitted in error.

* Associate Professor, Institute of Law for Science and Technology, National Tsing Hua University, Taiwan; LL.B., LL.M., National Taiwan University; LL.M. in Corporate Law, New York University School of Law; J.S.D., University of Illinois College of Law. Member, New York and Taiwan Bars. For helpful comments and insightful suggestions on the prior draft, we thank the anonymous reviewers. The standard disclaimers apply. Correspondence to Chang-hsien Tsai, Institute of Law for Science \& Technology, National Tsing Hua University, 101, Sec. 2, Kuang-Fu Road, HsinChu 30013, Taiwan. E-mail address: chstsai@mx.nthu.edu.tw; r90a21037@ntu.edu.tw.

** Ph.D. Candidate at European Doctorate in Law \& Economics (Erasmus University Rotterdam, the Netherlands; University of Hamburg, Germany; University of Bologna, Italy); BA in Economics, LL.M., National Tsing Hua University, Taiwan. I am cordially grateful to Associate Professor Chang-hsien Tsai for guiding me in co-authoring this paper. I am also thankful to my former colleagues within the Foxconn group who provided lots of deep insights for this paper. E-mail address: kjpeng15@gmail.com; kuan-jung.peng@edle-phd.edu.

\section{REFERENCE}

Tsai, Chang-hsien, \& Peng, Kuan-Jung (2017) "The FinTech Revolution and Financial Regulation:

The Case of Online Supply-Chain Financing." doi: https://doi.org/10.1017/als.2016.65. 